\title{
Disease-modifying therapies in relapsing-remitting multiple sclerosis
}

\author{
This article was published in the following Dove Press journal: \\ Neuropsychiatric Disease and Treatment \\ 8 July 2010 \\ Number of times this article has been viewed
}

\author{
Fabricio González-Andrade' \\ José Luis Alcaraz-Alvarez ${ }^{2}$ \\ 'Department of Medicine, \\ Metropolitan Hospital, Quito, \\ Ecuador; ${ }^{2}$ School of Medicine, \\ University of Mayab, Merida, Mexico
}

Correspondence: Fabricio González-Andrade Department of Medicine, Metropolitan Hospital,Av. Mariana

de Jesús Oe8 y Occidental,

170125, Quito, Ecuador

Tel +5932 2070715

Email fabriciogonzaleza@yahoo.es
Clinical question: What is the best current disease-modifying therapy for relapsing-remitting multiple sclerosis?

Results: The evidence shows that the most effective disease-modifying therapy for delaying short- to medium-term disability progression, prevention of relapses, reducing the area and activity of lesions on magnetic resonance imaging, with the least side effects, is high-dose, high-frequency subcutaneous interferon- $\beta 1 \mathrm{a} 44 \mu \mathrm{g}$ three times per week.

Implementation: The pitfalls in treatment of MS can be avoided by remembering the following points:

- The most effective therapy to prevent or delay the appearance of permanent neurological disability with the fewest side effects should be chosen, and treatment should not be delayed.

- Adherence to treatment should be monitored closely, and needs comprehensive patient information and education to establish long-term adherence, which is a critical determinant of long-term outcome.

- The correct approach to the disease includes disease management, symptom management, and patient management. A combination of tools is necessary to ease the various symptoms, which fall into three broad categories, i.e. rehabilitation, pharmacological, and procedural.

- It is important to understand that no treatment modality should be used alone, unless it is in itself sufficient to remedy the particular symptom/problem.

Keywords: relapsing-remitting multiple sclerosis, interferon, disease-modifying therapy, relapse prevention

\section{Multiple sclerosis}

Definition: Multiple sclerosis (MS) is a debilitating autoimmune disease, although some new studies have raised the possibility that there is more than one pathway to the final pathological changes, and that different pathways may predominate in different clinical forms of MS. ${ }^{1}$ It has two major components, ie, axonal degeneration and inflammation, resulting in loss of the myelin-coated axons in the central nervous system (CNS). ${ }^{2} \mathrm{MS}$ is most commonly seen in the adult Caucasian population of Western European ethnic origin, ${ }^{3}$ and most frequently affects women aged $20-40$ years. ${ }^{4} \mathrm{~A}$ definite diagnosis of MS requires the occurrence of at least two neurological events consistent with demyelination that are separated both anatomically in the CNS and temporally. ${ }^{5}$

There are three clinical forms of the disease, the most common being the relapsing-remitting form (RRMS), which is characterized by episodes of neurological 
impairment followed by complete or nearly complete recovery. ${ }^{6}$ It has been shown that the systemic administration of interferon-beta-1a (IFN $\beta 1$ a) decreases the frequency of exacerbations, slows the progression of physical disability, and reduces the development of brain lesions. ${ }^{7}$ IFN $\beta 1 \mathrm{a}$ is a 166-amino acid glycoprotein with a molecular weight of approximately $22,500 \mathrm{Da}$. It is produced by recombinant DNA technology using genetically engineered Chinese Hamster Ovary cells into which the human IFN $\beta$ gene has been introduced. ${ }^{4,8}$

Prevalence: Globally, the median estimated prevalence of MS is 30 per 100,000 , with a range of 5-80. Regionally, the median estimated prevalence of MS is highest in Europe at 80 per 100,000, followed by the Eastern Mediterranean (14.9 per 100,000), and the US (8.3 per 100,000). The countries reporting the highest estimated prevalence of MS are Hungary (176 per 100,000), Slovenia (150), Germany (149), and the US (135). ${ }^{9}$ The total estimated female:male ratio is around 2.0, and the prevalence rates reported are higher for women. ${ }^{10}$ Other studies in the US have reported a prevalence of 58-95 per 100,00. ${ }^{11}$ Moreover, in the past 25 years, prevalence studies of specific US regions have produced a range of estimates, up to 177 per 100,000 in Olmstead County, Minnesota. ${ }^{12}$

Incidence: Globally, the median incidence of MS is 2.5 per 100,000 . Regionally, the median estimated incidence of MS is greatest in Europe (3.8 per 100,000), followed by the Eastern Mediterranean (2), and the US (1.5). The countries reporting the highest estimated incidence of MS include Croatia (29), Iceland (10), and Hungary (9.8). ${ }^{9}$

Economics: From the perspective of the US health care payer, and considering only the direct medical costs, the cost per relapse is close to $4700 \mathrm{USD}$, and the cost per disability progression step is nearly 1800 USD. Subcutaneous (SC) IFN $\beta 1$ a injection, and glatiramer acetate had the most favorable costs per relapse avoided, and intramuscular (IM) IFN $\beta 1$ a injection had the least favorable cost-effectiveness ratio ( 142,000 USD per relapse avoided), in a two-year follow-up period, according to Goldberg et al. ${ }^{13}$ In other study, ${ }^{14}$ SC IFN $\beta 1$ a was predicted to enable more patients to avoid relapse. Total mean costs per patient (discounted) were $\sim 80,000$ USD with SC IFN $\beta 1$ a versus $\sim 74,000$ USD with IM IFN $\beta 1 \mathrm{a}$ administration, representing a net increase of 5400 USD per patient.

Levels of evidence: Systematic reviews, randomized clinical trials (RCTs), and general reviews.

Search sources: Medline (PubMed), Cochrane Library, The Cochrane Multiple Sclerosis Review Group NHS evidence (UK), DARE, EMBASE.

Outcomes: The major outcomes seen in most reports were delayed disability progression, prevention of relapses, reduced magnetic resonance imaging (MRI) lesion activity and area, decreasing side effects, long-term effects, and tolerability.

Consumer summary: MS may be related to the immune system. IFNs have several effects on the immune system, and act against viruses. IFN can help to reduce disability and exacerbations for people with MS in the medium term. IFN $\beta 1$ a administered IM or SC can lead to a moderate reduction in recurrences and disability in MS patients with remissions. The most common side effects are influenza-like symptoms, injection site reactions, pain in the joints and muscles, fatigue, and headache.

\section{The evidence}

Systematic reviews: 10

RCTs: 12

\section{Systematic reviews}

First-line treatment of RRMS is currently based on immunomodulatory drugs, including recombinant IFN $\beta 1$ a and IFN $\beta 1 b$ or glatiramer acetate, although the latter has been shown to be only modestly effective. Recently it has been suggested that nerve damage and inflammation are early events in MS evolution which immunomodulatory drugs can only partially prevent. This paper makes a critical comparison between the main treatments ${ }^{15-29}$ used in MS, to determine if IFN $\beta 1$ a is the best treatment.

\section{Interferon- $\beta$ Ia}

It has been hypothesized that the efficacy of IFN could be higher if it is used at the first appearance of symptoms, in Clinically Isolated Syndromes suggestive of demyelinating events, a pathology which carries a high risk of conversion to clinically definite MS. The efficacy of IFN $\beta 1$ a for exacerbations and disease progression in patients with RRMS was modest after one and two years of treatment. IFN administered by the oral route was not effective for prevention of relapses. Longer follow-up and more uniform reporting of clinical and MRI outcomes in these trials might have allowed for more convincing conclusions. ${ }^{15}$ Other research confirmed the efficacy of IFN $\beta 1$ a in preventing the conversion from a 
Clinically Isolated Syndrome to clinically definite MS over two years of follow-up. It could be useful for clinical practice if future analyses of the efficacy of IFN $\beta 1$ a treatment were undertaken in different patient subgroups, because patients in the studies reported to date have been clinically heterogeneous in terms of length of follow-up and clinical findings at the time of initial presentation. ${ }^{16}$

\section{Glatiramer acetate}

A Cochrane systematic review performed in 2003 concluded that glatiramer acetate did not show any beneficial effect on the main outcome measures in MS, and did not substantially affect the risk of clinical relapses. Therefore, its routine use in clinical practice was not supported. ${ }^{17}$ Nevertheless, the ongoing US glatiramer acetate trial is the longest evaluation of continuous sole disease-modifying therapy in RRMS. It has been concluded ${ }^{18}$ that MS patients with a mean disease duration of 22 years who were treated with glatiramer acetate for up to 15 years had reduced relapse rates, and decreased disability progression and transition to secondary progressive MS. There were no long-term safety issues. Patients with MS who have an unsatisfactory response to IFN $\beta$ should be considered for glatiramer acetate therapy. ${ }^{18}$

\section{Natalizumab}

An immunosuppressive drug, natalizumab was previously available for a short period of time for treatment of MS in the US. It was consistently more effective than placebo for both relapse-related outcomes and disease progression in two trials. ${ }^{19}$ One of those trials included IM IFN $\beta 1$ a used concomitantly with natalizumab and placebo arms; however, this did not appear to impact the findings of that trial in terms of efficacy outcomes. Natalizumab was initially suspended as a result of several confirmed cases of progressive multifocal leukoencephalopathy. ${ }^{19}$ The exact relationship between multifocal leukoencephalopathy and natalizumab is unknown. However, in 2005, the manufacturers suspended the supply of this drug from commercial distribution. ${ }^{20}$ After lengthy deliberation by an FDA advisory panel, natalizumab was reapproved in 2009, but with stringent restrictions including patient, provider, and site registration..$^{21}$ It is now considered as second-line therapy for patients who had failed first-line agents, i.e. IFN or glatiramer acetate.

\section{Intravenous immunoglobulins}

There is evidence to support the use of intravenous immunoglobulins (IVIG) as a preventative treatment for relapses in RRMS. There was no evidence of delay in progression of disease in secondary progressive MS, ${ }^{22}$ but this needs to be evaluated carefully in relapsing-remitting disease.

\section{Mitoxantrone}

This agent has partial efficacy, but due to its unclear long-term safety profile, it should be reserved for patients with worsening RRMS and evidence of worsening disability. ${ }^{23}$ Limited evidence from one small trial showed that mitoxantrone was more effective than placebo for both disease progression and relapse rates. ${ }^{23}$

\section{Azathioprine}

Azathioprine is a reasonable alternative to IFN $\beta 1$ a for treating MS. A logical next step for future trials would seem to be a direct comparison of azathioprine and IFN $\beta 1 \mathrm{a}$, which has yet to be done. ${ }^{24}$ Better evidence of the effects of this drug is needed.

\section{Aminopyridines}

These agents are possibly useful for treating MS symptoms, although the available information does not allow any objective statement about their safety or efficacy. Publication bias remains a pervasive problem in this area, and until the results of as yet unpublished studies are available to the scientific community, no confident estimate of the effectiveness of the aminopyridines in the management of MS symptoms is possible. ${ }^{25}$

\section{Cyclophosphamide}

Cyclophosphamide is an immunosuppressive drug used for various autoimmune diseases, although its use for MS has not been well studied. In the pertinent literature, there are scant data available to show that cyclophosphamide slows MS progression in the medium term. It has been noted that side effects, including alopecia, nausea, vomiting, and amenorrhea occur at high frequency, and there is also evidence to suggest adverse effects appearing after two years of treatment. ${ }^{26}$

\section{Methotrexate}

The only study of methotrexate in progressive MS revealed a nonsignificant trend in sustained reduction of disease progression on the Expanded Disability Status Scale and number of relapses in favor of methotrexate. However, as yet, there are not enough studies of methotrexate in RRMS to reach any firm conclusions. ${ }^{27}$

\section{Hyperbaric oxygen therapy}

This treatment modality involves people breathing pure oxygen in a specially designed chamber. Hyperbaric oxygen 
therapy has sometimes been used for MS, especially in cases of lack of oxygen to the affected nerves leading to worsening MS, but this theory is unproven. There is no consistent evidence to confirm a beneficial effect of hyperbaric oxygen therapy for the treatment of MS, and its routine use is not justified. The analyses suggestive of benefit were isolated, biologically implausible, and would need to be confirmed in well-designed trials in the future. ${ }^{28}$

\section{Other therapies}

Emerging immunosuppressive therapies in oncology and organ transplantation have been associated with life-threatening risks, including serious opportunistic infections and/or new malignancies. ${ }^{39}$ Among these drugs are cladribine, alemtuzumab, rituximab, and fingolimod. With alemtuzumab, the greatest risk seems to be the development of autoimmune syndromes. The effects of cladribine, alemtuzumab, and rituximab on the immune system are more long term, and must be monitored years rather than for days or weeks. Other drugs, such as laquinimod and dimethyl fumarate, appear to be largely immunomodulatory, whereas teriflunomide is mainly immunosuppressive, i.e. preventing lymphocyte proliferation. Laquinimod, dimethyl fumarate, and teriflunomide are not associated with these life-threatening risks, and they seem to be safer. However, some questions remain about how robust the efficacy of these therapies will be..$^{39,40}$ There are not enough systematic reviews supporting evidence on the effect of daclizumab, amtuzumab, and alemtuzumab in RRMS. ${ }^{29}$ Alternative therapies, including bone marrow autologous transplantation and plasmapheresis, did not showed definitive results neither. A number of small clinical trials ${ }^{24-27}$ supported the modest effect of IVIG, azathioprine, methotrexate, and cyclophosphamide, either alone or in combination with standard therapy.

\section{Randomized clinical trials}

Twelve RCTs were found $d^{4,8,33,47-54}$ and their results are shown in the Table 1.

\section{SC IFN $\beta$ I a versus SC IFN $\beta$ Ib}

IFN $\beta 1$ a has shown better outcomes in RRMS, causing fewer side effects and less immunogenicity. SC IFN $\beta 1$ a and SC IFN $\beta 1 \mathrm{~b}$ were similarly effective in reducing the frequency of relapses and slowing disease progression, whereas IM IFN $\beta 1$ a was less effective. However, these findings were contradicted by trials which compared each drug with placebo. IM IFN $\beta 1$ a was similar to IFN $\beta 1$ b for preventing relapses, while SC IFN $\beta 1$ b was not significantly better than placebo for slowing disease progression.

\section{IFN $\beta$ I used alone or as combination therapy}

There was weak evidence showing that IFN $\beta 1$ a in combination with other drugs increases favorable outcomes in MS. Many preliminary studies have produced favorable results for various combination regimens. For instance, add-on, highdose daclizumab treatment reduces the number of new or enlarged gadolinium contrast-enhancing lesions, and might reduce MS disease activity to a greater extent than IFN $\beta 1$ a alone, ${ }^{29}$ and oral methylprednisolone given in pulses every four weeks as an add-on therapy to SC IFN $\beta 1$ la in patients with RRMS led to a significant reduction in relapse rate. ${ }^{30}$ However, several subsequent large, randomized, controlled trials have had negative or conflicting results. ${ }^{31}$ Therefore, the usefulness of combination therapy in MS remains uncertain.

\section{Subcutaneous versus intramuscular IFN $\beta$ I}

There is no clear evidence that the SC route is better than the IM route, although tolerability problems, especially related to injections and injection site reactions with the IM route (including lipoatrophy), continue to be an important issue. However, in general terms, the SC route has had better acceptance by patients and the most favorable adherence to treatment. Two trials suggested a benefit of SC IFN $\beta 1$ a over interferon IM IFN $\beta 1 \mathrm{a}$ in terms of relapse outcomes. In addition, another study has shown that SC IFN $\beta 1$ had dosedependent cognitive benefits in mildly disabled patients with RRMS, and supported the idea of early initiation of high-dose IFN $\beta 1$ a treatment. ${ }^{32}$ On the other hand, the ASSURANCE study concluded that for some patients with MS, long-term use of IM IFN $\beta 1$ a was associated with significantly less disability progression, better quality of life, and greater independence in activities of daily living. ${ }^{33}$ Therefore, the only real, but weak, difference between the SC and IM routes would be acceptance and convenience for patients.

\section{Optimal duration of effect of IFN $\beta$ I}

One RCT showed that SC IFN $\beta 1$ a would yield greater health benefits over four years than IM IFN $\beta 1 \mathrm{a}$, at a cost that would seem to be a reasonable trade-off. In the long term, IM IFN $\beta 1$ a also showed a beneficial safety-tolerability profile. IM IFN $\beta 1$ a was well tolerated, and no new safety concerns were identified over 15 years of use. ${ }^{33}$ Despite that, there have not been enough trials that show significant beneficial effects in delaying disability progression with long-term therapy (over 20 years or more), with any of the IFNs. The methodological difficulties faced in designing a trial of such an extended duration would be hard to overcome. 


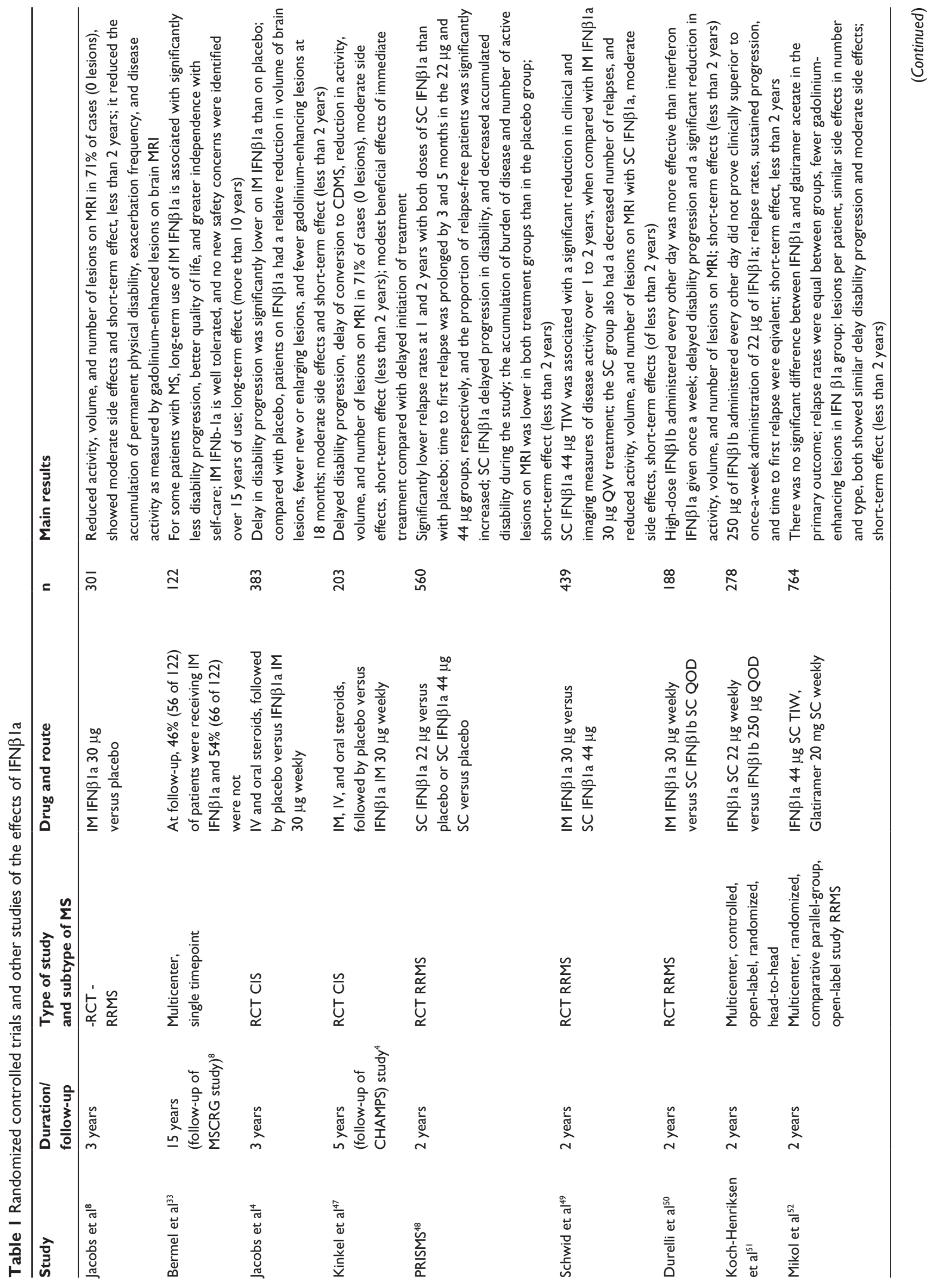




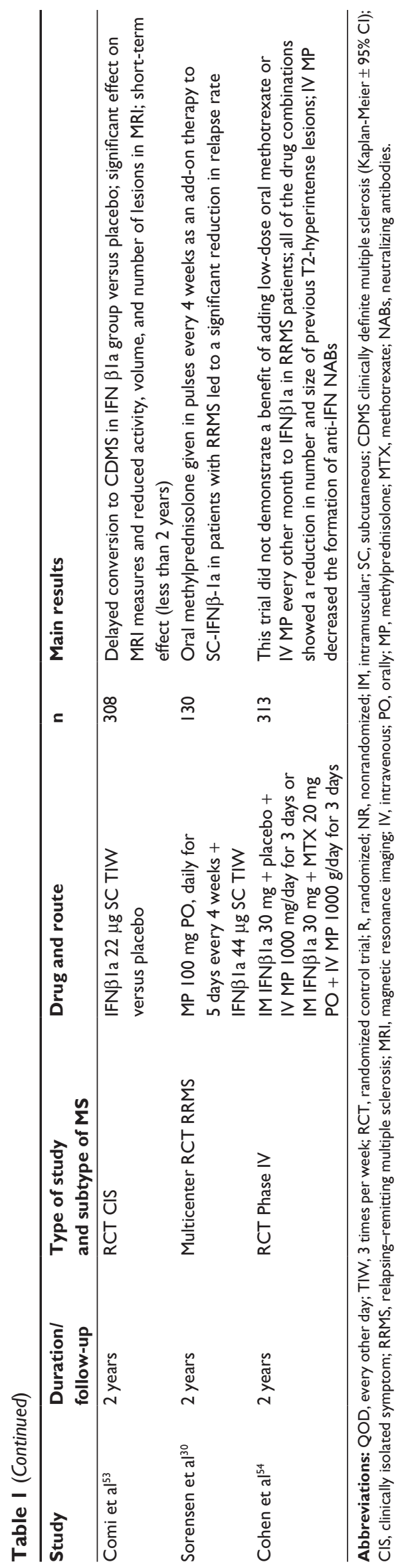

\section{Low- versus high-dose IFN therapy}

SC IFN $\beta 1 \mathrm{a} 44 \mu \mathrm{g}$ has shown the highest efficacy in the treatment of RRMS. ${ }^{34}$ Long-term Class 1 data from PRISMS supported the use of SC IFN $\beta 1$ a twice weekly as a first-line treatment for MS, as evidenced by sustained efficacy rates, acceptable safety profiles, and high patient adherence rates. ${ }^{34}$

\section{Frequency of administration}

SC IFN $\beta 1$ a demonstrated better outcomes in RRMS at a dosing frequency of three times per week. Two RCTs concluded that administering high-dose, high-frequency SC IFN $\beta 1$ a was more effective in preventing relapses in patients with RRMS than low-dose weekly IM IFN $\beta 1$ after 64 weeks. ${ }^{34,35}$

\section{IFN $\beta$ I versus glatiramer acetate}

Both these drugs have been used as first-line treatment for RRMS in RCTs. The mean difference in relapse rate between glatiramer acetate and placebo was statistically significant in some trials, but the effect on disease progression was unclear. ${ }^{37}$ Adverse events rates were higher for glatiramer acetate than for placebo, most notably post-injection systemic reactions and injection site reactions, as were withdrawals due to adverse events. Withdrawal rates were also consistently significantly higher in observational studies when compared with placebo. The use of glatiramer acetate in cases of suboptimal response to IFNs appeared to improve the effectiveness of the latter. However, IFN $\beta 1$ has showed better results than glatiramer acetate in most cases.

\section{Suboptimal responses}

The frequency of suboptimal responses to MS therapy was as high as $30 \%$ in the three years following initiation of first-line therapies ${ }^{36}$ Criteria for defining a suboptimal response vary between the trials. Typical criteria include relapse rates greater than one per year or unchanged from pretreatment rates, incomplete recovery from relapses, new brainstem or spinal cord lesions, and progression of disability or cognitive impairment that leads to a disruption in activities of daily living. There are at least three main causes of suboptimal responses. ${ }^{37}$ These are development of neutralizing antibodies (NABs) that reduce or abolish IFN $\beta$ bioactivity in a titer-dependent manner, lack of long-term adherence to therapy, and, possibly, switching of disease-modifying therapies to improve patient response or eliminate adverse effects.

\section{Adherence to therapy}

Lack of adherence was shown in some RCTs. Notably, four of the six currently available therapies require self-injection, and 
all have side effects ranging from influenza-like symptoms to injection site reactions. Barriers to adherence included needle phobia, not taking medication because of forgetfulness, complacency, treatment fatigue, changes in socioeconomic status, and perceived lack of efficacy. ${ }^{36}$ The most common adverse events overall were injection site reactions, vasodilatation, rash, dyspnea, and chest pain. Localized lipoatrophy occurred in roughly $2 \%$ of patients. ${ }^{37}$

\section{Neutralizing antibodies}

Some reports ${ }^{38,39}$ showed that the appearance of high-titer $(<1: 100)$ neutralizing NABs totally blocked the biological activity of IFN $\beta$. The development of NABs did occur in up to $35 \%$ of IFN $\beta$-treated patients, with several studies suggesting that IFN $\beta 1 \mathrm{~b}$ was most immunogenic $(35 \%$ of patients NAB-positive), followed by subcutaneous IFN $\beta 1$ a (23.7\% of patients NAB-positive), and, lastly, IM IFN $\beta 1$ a (7\% of patients NAB-positive). ${ }^{40}$

\section{Conclusions}

Thus far, the evidence shows that the most effective shortto medium-term, disease-modifying therapy for delaying disability progression, prevention of relapses, reducing the area and activity of lesions seen on MRI, with the least side effects, is high-dose, high-frequency SC IFN $\beta 1$ a $44 \mu \mathrm{g}$ three times per week

\section{The Practice}

\section{Avoiding pitfalls}

- The most effective therapy with the least side effects should be started as soon as possible to prevent or delay the appearance of permanent neurological disability

- Adherence to treatment should be monitored closely, and comprehensive patient information and education is necessary to establish long-term adherence, which is a critical determinant of long-term outcome.

- The best approach to treatment of the disease includes disease management, symptom management, and patient management. A combination of tools is necessary to ease the various symptoms that fall into three broad categories, i.e. rehabilitation, pharmacological, and procedural. It is important to understand that none of these treatment approaches should be used in isolation, unless it is by itself sufficient to remedy the particular symptom/ problem.

\section{Management}

Patients who have an unsatisfactory response to IFN $\beta 1$ should be considered for glatiramer acetate therapy. This should be started early in the course of MS to minimize irreversible axonal damage. Patients with worsening MS may be referred for mitoxantrone therapy, but short- and long-term adverse effects, including cardiotoxicity, must be monitored for closely. To shorten the duration of MS relapses and accelerate recovery, corticosteroid therapy should be considered. MRI should be repeated every three months after a clinically suspicious episode to facilitate early diagnosis of MS.

\section{Assessment}

Magnetic resonance imaging of brain

MRI scan of the brain is the most useful test for confirming the diagnosis of MS. The lesions appear as areas of high signal, predominantly in the cerebral white matter or spinal cord, on T2-weighted images. ${ }^{41}$

\section{Multimodal evoked potentials}

Multimodal evoked potentials may be useful for demonstrating the presence of subclinical lesions in sensory pathways. The presence of three abnormal multimodal evoked potentials increases the risk of reaching moderate disability independently of baseline MRI. ${ }^{42}$

\section{Cerebrospinal fluid analysis}

The CSF immunoglobulin $\mathrm{G}$ concentration is increased relative to other CSF proteins (eg, albumin), and CSF gel electrophoresis reveals oligoclonal bands that are not present in a matched serum sample. ${ }^{43}$

\section{Local physical findings}

Some symptoms could be explained by localized disease: the presence of steadily progressive disease, the absence of clinical remission, the absence of oculomotor, optic nerve, sensory, or bladder involvement, and normal CSF findings. However, none of these findings exclude the diagnosis of MS. ${ }^{44}$

\section{Treatment}

The evidence shows that the most effective disease-modifying therapy at this time is high-dose, high-frequency SC IFN $\beta 1$ (44 $\mu \mathrm{g}$ three times per week alone). The major difference between the IFN $\beta 1$ drugs is that IM IFN $\beta 1 \mathrm{a}$ is given once 
Table 2. Current drugs used in relapsing-remitting multiple sclerosis.

\begin{tabular}{|c|c|c|c|c|c|}
\hline Drug & Brand name & Delivery systems & Dosage & Side effects & Monitoring \\
\hline IFN $\beta$ - I a (IM) & Avonex $^{\circledR}$ & $\begin{array}{l}\text { Reconstitution } \\
\text { needed/prefilled syringe }\end{array}$ & $\begin{array}{l}30 \mu \mathrm{g} \text { IM once } \\
\text { weekly }\end{array}$ & Influenza-like symptoms & CBC, LFTs \\
\hline IFN $\beta$ - I a (SC) & Rebif $^{\circledR}$ & Ready to use prefilled syringe & $\begin{array}{l}22-44 \mu g \text { SC three } \\
\text { times weekly }\end{array}$ & $\begin{array}{l}\text { Influenza-like symptoms and } \\
\text { injection site reactions }\end{array}$ & CBC, LFTs \\
\hline IFN $\beta$-Ib (SC) & Betaseron $^{\circledR}$ & Reconstitution needed & $\begin{array}{l}0.25 \mathrm{mg} \text { SC every } \\
\text { other day }\end{array}$ & $\begin{array}{l}\text { Influenza-like symptoms and } \\
\text { injection site reactions; }\end{array}$ & CBC, LFTs \\
\hline Glatiramer acetate & Copoxone ${ }^{\circledR}$ & Ready to use prefilled syringe & 20 mg SC once daily & $\begin{array}{l}\text { injection site reactions and a } \\
\text { benign systemic reaction } \\
\text { (flushing, chest tightness with } \\
\text { racing or pounding } \\
\text { heartbeat, anxiety, and } \\
\text { difficulty in breathing) }\end{array}$ & $\begin{array}{l}\text { Local site of } \\
\text { injection }\end{array}$ \\
\hline $\begin{array}{l}\text { Mitoxantrone } \\
\text { (immunosuppressive) }\end{array}$ & Novantrone $^{\circledR}$ & $\begin{array}{l}\text { Injection concentrate supplied, } \\
\text { dilution required }\end{array}$ & $\begin{array}{l}5 \text { to } 12 \mathrm{mg} \text { per } \mathrm{m}^{2} \\
\text { IV every } 3 \text { months }\end{array}$ & $\begin{array}{l}\text { Mild chemotherapy-related } \\
\text { side effects, cumulative } \\
\text { cardiotoxicity, small } \\
\text { increased risk of leukemia }\end{array}$ & $\begin{array}{l}\text { CBC, } \\
\text { cardiological } \\
\text { assessment }\end{array}$ \\
\hline
\end{tabular}

Abbreviations: IFN, interferon; IM, intramuscular; SC, subcutaneous; IV, intravenous; CBC, complete blood count; LFTs, liver function tests.

a week and SC IFN $\beta 1 \mathrm{a}$ and IFN $\beta 1 \mathrm{~b}$ are given three times a week, or every other day, respectively. The main differences between the available immunomodulatory drugs are shown in Table 2. Treatment with any IFN $\beta$ agent can result in the development of NABs. Although study results are variable, once-weekly IM IFN $\beta 1$ a therapy has been reported to have the lowest incidence of NAB development. ${ }^{46}$

\section{Symptomatic therapy}

There is no clear evidence that symptomatic therapy is useful for all patients. Response is dependent on the stage of the disease and on the affective and psychiatric status of the patient, although some medications can be used to improve symptoms partially. ${ }^{44}{ }^{46}$ Influenza-like symptoms, including fever, chills, malaise, muscle pain, and fatigue are the most common side effects, and usually dissipate with continued therapy and premedication with a nonsteroidal anti-inflammatory drug. Dose titration at the initiation of IFN $\beta$ therapy is also a useful strategy. Other side effects of IFN $\beta$ include injection site reactions, depression, mild anemia, thrombocytopenia, elevated transaminase levels, and worsening of pre-existing spasticity. These are not usually severe and rarely lead to discontinuation of treatment. ${ }^{45}$

\section{Disclosure}

The authors report no conflicts of interest in this work.

\section{References}

1. Lucchinetti C, Brück W, Parisi J, Scheithauer B, Rodriguez M, Lassmann H. Heterogeneity of multiple sclerosis lesions: Implications for the pathogenesis of demyelination. Ann Neurol. 2000;47:707-717.

2. Kasper LH, Shoemaker J. Multiple sclerosis immunology. The healthy immune system vs the MS immune system. Neurology. 2010;74 (Suppl 1):S2-S8.
3. Polman C, Reingold S, Edan G, et al. Diagnostic Criteria for Multiple Sclerosis: 2005 Revisions to the "McDonald Criteria". Ann Neurol. 2005;58:840-846.

4. Jacobs LD, Beck R, Simon J, et al. Intramuscular interferon beta-1a therapy initiated during a first demyelinating event in multiple sclerosis. CHAMPS Study Group. $N$ Engl J Med. 2000;343(13):898-904.

5. McDonald WI, Compston A, Edan G, et al. Recommended diagnostic criteria for multiple sclerosis: Guidelines from the International Panel on the Diagnosis of Multiple Sclerosis. Ann Neurol. 2001;50:121-127.

6. McDonald WI. Relapse, remission, and progression in multiple sclerosis. N Engl J Med. 2000;343(20):1486-1487.

7. Cohen JA, Calabresi PA, Chakraborty S, et al. Avonex combination trial in relapsing-remitting MS: Rationale, design and baseline data. Mult Scler. 2008;14:370-382.

8. Jacobs LD, Cookfair DL, Rudick RA, et al. Intramuscular interferon beta-1a for disease progression in relapsing multiple sclerosis. Ann Neurol. 1996;39(3):285-294.

9. World Health Organization and Multiple Sclerosis International Federation. Atlas: Multiple Sclerosis Resources in the World. Geneva: World Health Organization Press; 2008.

10. Pugliatti M, Rosati G, Carton H, et al. The epidemiology of multiple sclerosis in Europe. Eur J Neurol. 2006;13(7):700-722.

11. Williamson DM, Noonan CW, Henry JP, et al. The prevalence of multiple sclerosis in 3 US communities. Prev Chronic Dis. 2010;7(1):A12.

12. Mayr WT, Pittock SJ, McClelland RL, Jorgensen NW, Noseworthy JH, Rodriguez M. Incidence and prevalence of multiple sclerosis in Olmsted County, Minnesota 1985-2000. Neurology. 2003;61(10):1373-1377.

13. Goldberg LD, Edwards NC, Fincher C, Doan QV, Al-Sabbagh A, Meletiche DM. Comparing the cost-effectiveness of disease-modifying drugs for the first-line treatment of relapsing-remitting multiple sclerosis. J Manag Care Pharm. 2009;15(7):543-555.

14. Guo S, Bozkaya D, Ward A, O'Brien JA, Ishak K, Bennett R. Treating relapsing multiple sclerosis with subcutaneous versus intramuscular interferon-beta-1a: Modelling the clinical and economic implications. Pharmacoeconomics. 2009;27(1):39-53.

15. Rice GPA, Incorvaia B, Munari LM, et al. Interferon in relapsing-remitting multiple sclerosis. Cochrane Database Syst Rev. 2001:CD002002.

16. Clerico M, Faggiano F, Palace J, Rice GPA, Tintorè Subirana M, Durelli L. Recombinant interferon beta or glatiramer acetate for delaying conversion of the first demyelinating event to multiple sclerosis. Cochrane Database Syst Rev. 2008:CD005278.

17. Munari LM, Lovati R, Boiko A. Therapy with glatiramer acetate for multiple sclerosis. Cochrane Database Syst Rev. 2003;CD004678. 
18. Ford C, Goodman A, Johnson K, et al. Continuous long-term immunomodulatory therapy in relapsing multiple sclerosis: Results from the 15-year analysis of the US prospective open-label study of glatiramer acetate. Mult Scler. 2010;16(3):342-350.

19. Linda H, von Heijne A, Major EO, Ryschkewitsch C, Berg J, Olsson T, Martin C. Progressive multifocal leukoencephalopathy after natalizumab monotherapy. $N$ Engl J Med. 2009;361(11):1081-1087.

20. Jilek S, Jaquiéry E, Hirsch HH, et al. Immune responses to JC virus in patients with multiple sclerosis treated with natalizumab: A crosssectional and longitudinal study. Lancet Neurol. 2010;9(3):264-272.

21. Brown BA. Natalizumab in the treatment of multiple sclerosis. Ther Clin Risk Manag. 2009;5:585-594.

22. Gray O, McDonnell GV, Forbes RB. Intravenous immunoglobulins for multiple sclerosis. Cochrane Database Syst Rev. 2003:CD002936.

23. Martinelli Boneschi F, Rovaris M, Capra R, Comi G. Mitoxantrone for multiple sclerosis. Cochrane Database Syst Rev. 2005:CD002127.

24. Casetta I, Iuliano G, Filippini G. Azathioprine for multiple sclerosis. Cochrane Database Syst Rev. 2007:CD003982.

25. Solari A, Uitdehaag BMJ, Giuliani G, Pucci E, Taus C. Aminopyridines for symptomatic treatment in multiple sclerosis. Cochrane Database Syst Rev. 2002:CD001330.

26. La Mantia L, Milanese C, Mascoli N, D'Amico R, Weinstock-Guttman B. Cyclophosphamide for multiple sclerosis. Cochrane Database Syst Rev. 2007:CD002819

27. Gray O, McDonnell GV, Forbes RB. Methotrexate for multiple sclerosis. Cochrane Database Syst Rev. 2004:CD003208.

28. Bennett MH, Heard R. Hyperbaric oxygen therapy for multiple sclerosis. Cochrane Database Syst Rev. 2004:CD003057.

29. Wynn D, Kaufman M, Montalban X, et al. Daclizumab in active relapsing multiple sclerosis (CHOICE study): A phase 2, randomised, double-blind, placebo-controlled, add-on trial with interferon beta. Lancet Neurol. 2010;4422(10):70033-70038.

30. Sorensen PS, Mellgren SI, Svenningsson A, et al. NORdic trial of oral Methylprednisolone as add-on therapy to Interferon beta-1a for treatment of relapsing-remitting Multiple Sclerosis (NORMIMS study): A randomised, placebo-controlled trial. Lancet Neurol. 2009;8(6):519-529.

31. Conway D, Cohen JA. Combination therapy in multiple sclerosis. Lancet Neurol. 2010;9(3):299-308.

32. Patti F, Amato MP, Bastianello S, et al. Effects of immunomodulatory treatment with subcutaneous interferon beta-1a on cognitive decline in mildly disabled patients with relapsing-remitting multiple sclerosis. Mult Scler. 2010;16(1):68-77.

33. Bermel RA, Weinstock-Guttman B, Bourdette D, Foulds P, You X, Rudick R. Intramuscular interferon beta-1a therapy in patients with relapsing-remitting multiple sclerosis: A 15-year follow-up study. Mult Scler. Feb 18, 2010. [Epub ahead of print]

34. Cohen BA, Rivera VM. PRISMS: The story of a pivotal clinical trial series in multiple sclerosis. Curr Med Res Opin. 2010;26(4):827-838.

35. Guo S, Bozkaya D, Ward A, O'Brien JA, et al. Treating relapsing multiple sclerosis with subcutaneous versus intramuscular interferon-beta-1a: Modelling the clinical and economic implications. Pharmacoeconomics. 2009;27(1):39-53.

36. Gauthier SA, Glanz BI, Mandel M, et al. Incidence and factors associated with treatment failure in the CLIMB multiple sclerosis cohort study. J Neurol Sci. 2009;284(1-2):116-119.

37. Cohen BA, Khan O, Jeffery DR, et al. Identifying and treating patients with suboptimal responses. Neurology. 2004;63(12 Suppl 6): S33-S40.

Neuropsychiatric Disease and Treatment

\section{Publish your work in this journal}

Neuropsychiatric Disease and Treatment is an international, peerreviewed journal of clinical therapeutics and pharmacology focusing on concise rapid reporting of clinical or pre-clinical studies on a range of neuropsychiatric and neurological disorders. This journal is indexed on PubMed Central, the 'PsycINFO' database and CAS, and is the official
38. Sorensen PS, Deisenhammer F, Duda P, et al. Guidelines on use of anti-IFN- $\beta$ antibody measurements in multiple sclerosis: Report of an EFNS Task Force on IFN- $\beta$ antibodies in multiple sclerosis. Eur $J$ Neurol. 2005;12(11):817-827.

39. Johnson KP. Risks vs benefits of glatiramer acetate: A changing perspective as new therapies emerge for multiple sclerosis. Ther Clin Risk Manag. 2010;6:153-172.

40. Rudick RA, Polman CH. Current approaches to the identification and management of breakthrough disease in patients with multiple sclerosis. Lancet Neurol. 2009;8(6):545-559.

41. McDonald WI, Compston A, Edan G, et al. Recommended diagnostic criteria for multiple sclerosis: Guidelines from the International Panel on the diagnosis of multiple sclerosis. Ann Neurol. 2001;50:121-127.

42. Pelayo R, Montalban X, Minoves T, et al. Do multimodal evoked potentials add information to MRI in clinically isolated syndromes? Mult Scler. 2010;16(1):55-61.

43. Luque FA, Jaffe SL. Cerebrospinal fluid analysis in multiple sclerosis. Int Rev Neurobiol. 2007;79:341-56.

44. Schapiro RT. The symptomatic management of multiple sclerosis. Ann Indian Acad Neurol. 2009;12(4):291-295.

45. Calabresi PA. Diagnosis and management of multiple sclerosis. Am Fam Physician. 2004;70(10):1935-1944.

46. Bertolotto A, Malucchi S, Sala A, et al. Differential effects of three interferon betas on neutralising antibodies in patients with multiple sclerosis: A follow up study in an independent laboratory. J Neurol Neurosurg Psychiatry. 2002;73(2):148-153.

47. Kinkel RP, Kollman C, O'Connor P, et al. IM interferon beta-1a delays definite multiple sclerosis 5 years after a first demyelinating event. Neurology. 2006;66(5):678-684.

48. PRISMS Study group. Randomized double-blind placebo-controlled study of interferon beta-1a in relapsing/remitting multiple sclerosis. PRISMS (Prevention of Relapses and Disability by Interferon beta-1a Subcutaneously in Multiple Sclerosis) Study Group. Lancet. 1998;352(9139):1498-1504.

49. Schwid SR, Panitch HS. Full results of the Evidence of Interferon DoseResponse-European North American Comparative Efficacy (EVIDENCE) study: A multicenter, randomized, assessor-blinded comparison of lowdose weekly versus high-dose, high-frequency interferon beta-1a for relapsing multiple sclerosis. Clin Ther. 2007;29(9):2031-2048.

50. Durelli L, Verdun E, Barbero P, et al; Independent Comparison of Interferon (INCOMIN) Trial Study Group. Every-other-day interferon beta-1b versus once-weekly interferon beta-1a for multiple sclerosis: Results of a 2 year prospective randomized multicenter study (INCOMIN). Lancet. 2002;359:1453-1460

51. Koch-Henriksen N, Sørensen PS, Christensen T, et al; Danish Multiple Sclerosis Group. A randomized study of two interferon-beta treatments in relapsing-remitting multiple sclerosis. Neurology. 2006;66(7):1056-1060.

52. Mikol DD, Barkhof F, Chang P, et al. Comparison of subcutaneous interferon beta-1a with glatiramer acetate in patients with relapsing multiple sclerosis (the REbif vs Glatiramer Acetate in Relapsing MS Disease [REGARD] study): A multicentre, randomized, parallel, openlabel trial. Lancet Neurol. 2008;7(10):903-914.

53. Comi G, Filippi M, Barkhof F, et al; ETOMS study group. Effect of early interferon treatment on conversion to definite multiple sclerosis; a randomised study: The ETOMS trial. Lancet. 2001;357:1576-1582.

54. Cohen JA, Imrey PB, Calabresi PA, Edwards KR, Eickenhorst T, Felton WL 3rd. Results of the Avonex Combination Trial (ACT) in relapsingremitting MS. Neurology. 2009;72(6):535-541.

Dovepress

journal of The International Neuropsychiatric Association (INA). The manuscript management system is completely online and includes a very quick and fair peer-review system, which is all easy to use. Visit http://www.dovepress.com/testimonials.php to read real quotes from published authors. 